\title{
Gamma Scalping using Neural Network with Heikinashi Transformed Data and its Performance
}

\author{
Nishchal Sharma \\ Department of Computer Science, Govt. College Kullu, Himachal Pradesh, India
}

\begin{abstract}
Article Info

Volume 7, Issue 1

Page Number: 255-259

Publication Issue :

January-February-2021

Article History

Accepted : 20 Feb 2021

Published : 28 Feb 2021

This research paper explores the usefulness of a neural network in portfolio management using gamma scalping. Since gamma scalping requires both stock options position as well as the underlying stock to be added or removed frequently. It becomes important to optimize such transactions. The underlying portfolio provides enough data points that may be used to calculate precise points of time to initiate stock addition or removal.

Keywords: Gamma Scalping, Heikinashi data, Neural Network, portfolio management.
\end{abstract}

\section{INTRODUCTION}

Electronic Portfolio management has become a key method for many investment banks or portfolio managers. Although using equity alone may expose many such institutions to high risk. So many institution create hedges with the help of options.

Gamma scalping is technique where an institution hedges its open option position with the help of stocks to create a delta neutral position. This method create profits when the underlying moves to either side. So the institution's risk for a particular position vanishes. However such position create a theta loss from the options that are being held by institution. Institution may add or remove stock in order to remain delta neutral, this creates a portfolio that is independent from direction but suffers losses with the passage of time.
However if the underlying create enough gamma, the institution can book it and overcome the theta loss that may arise from such position. But this requires precise timing as booking too early may waste future gamma gains and booking too late may result from huge theta losses.

This is where we use an artificial neutral network to understand the underlying pattern of stock movement and create hot spots where a portfolio may book its gamma value.

As it has been shown [1],[2] that neutral network perform extremely well in gauging sentiment and direction of underlying stock. Many researcher [3],[4] has demonstrated the usefulness of neural network in stock selections. The use of Markov chain [4],[5] and hidden Markov model has provided better signals for forecasting. Researcher [6] have provided enough

Copyright: (C) the author(s), publisher and licensee Technoscience Academy. This is an open-access article distributed under the terms of the Creative Commons Attribution Non-Commercial License, which permits unrestricted noncommercial use, distribution, and reproduction in any medium, provided the original work is properly cited 
evidence the use of SVM and [7] genetic algorithms to be useful in chaotic systems.

Better price discoveries and stock market sentiment analysis [8],[9] has been studied for many foreign exchanges. Many researchers have used various method to transform [10],[11],12]stock market data and provide better signals using neural network.

This paper describes a system that provides action points using neural network that allows portfolio managers to book profits in a delta neutral positions.

\section{METHODS AND MATERIAL}

Here we discuss the basic method of delta neutral positions and Heikinashi Transformation method. We will use a Heikinashi transformed data to train network and then create a delta neutral portfolio.

\section{Heikinashi Transformation rules:}

Let $\mathrm{O}_{\text {current}}, \mathrm{H}_{\text {current }}$, Lcurrent, $\mathrm{C}_{\text {current }}$ represents current open, high, low, close values.

Let OPrev, HPrev, LPrev, CPrev represents Previous day/period open, high, low, close values.

Then Heikin-Ashi values (HA) are calculated as:-

$\mathrm{HA}-$ close $=\left(\mathrm{O}_{\text {current }}+\mathrm{H}_{\text {current }}+\mathrm{L}_{\text {current }}+\mathrm{C}_{\text {current }}\right) / 4$

HA-Open $=($ HA-OpenPrev + HA-ClosePrev $) / 2$

$\mathrm{HA}-\mathrm{High}_{\mathrm{g}}=$ Maximum of the $\mathrm{H}_{\text {current }}, \mathrm{HA}$-Open or HA-close HA-Low $=$ Minimum of the Lcurrent, $\mathrm{HA}$-Open or HA-close

\section{A. Delta neutral position}

Delta neutral position can be created by buying both call and put option, such position have positive gamma but negative theta value.
Lets say that $\mathrm{Q}$ represents the entire portfolio with $\mathrm{P}$ being Puts and $C$ being calls. Lets say that $n$ represents no of lots of both calls and puts.

So $\mathrm{Q}=\mathrm{n}(\mathrm{P}+\mathrm{C})$

lets say that $(\mathrm{P}+\mathrm{C})$ has a combined daily theta value $\mathrm{T}$. So net daily theta value of entire portfolio is $=n T$

Lets say Gamma generated over a period of $Z$ is $G$.

Net theta loss for $\mathrm{Z}$ days $=\mathrm{nTZ}$

Net Gamma Gain is = G

Total value of stock present in portfolio $=\mathrm{S}$

For a profitable portfolio we need to have G>nTZ.

If $\mathrm{G}>\mathrm{nTZ}$ we can initiate to add or remove stock to again make entire portfolio delta neutral again. This is because one of the call and puts will have a greater delta value and entire portfolio will either have a positive delta or a negative delta.

Over all value of portfolio is given by

$\mathrm{Q}=\mathrm{n}(\mathrm{P}+\mathrm{C})+\mathrm{S}$

We measure the percentage gain or loss value of Portfolio by $\mathrm{Q}_{\text {net }}$ Over 30 days.

For a positive delta, we sell stocks to book gamma.

For a negative delta, we add stocks to book gamma.

Our system uses a $[4,3,3,1]$ neutral network with 2 hidden layers. The final output is a value between $[0,1.0] 0$ being low action point and 1being the highest action point.

\section{RESULTS AND DISCUSSION}

Following are the result from the system. As is evident from below diagram, we have a poor success below $30 \%$ prediction value. Above $30 \%$ prediction rate we start to see mainly positive results. The standard deviation is on the high side, which may denote a fine tuning may be needed. But over all results are vary convincing that we can fine tune such system for Gamma scalping. 


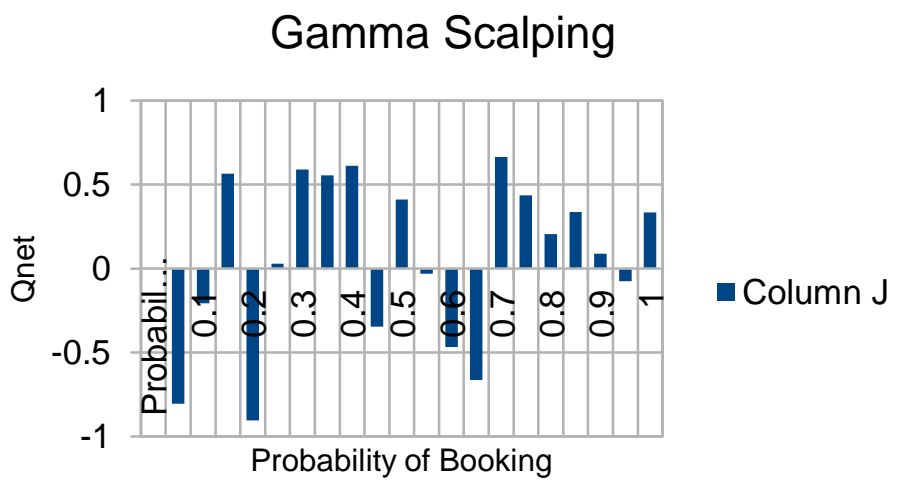

Figure 1. Results of simulation for a $[4,3,3,1]$ neural network.

\section{Standard Deviation $\quad 0.49$ \\ Average $\quad 0.07$}

Average Portfolio Return below 30\%

rate $\quad-0.12$

Average Portfolio Return over 30\%rate $\quad 0.15$

\section{A. Structure of Neural Network}

This paper doesn't test the system with different structure of neural network, which may be significant for a fine tuned performance. This also opens up the possibility of further research in above method.

\section{B. Title and Author Details}

Author: Assistant Professor Nishchal Sharma is a faculty at Govt. College Kullu of Computer Science and Application.

\section{CONCLUSION}

It is evident that a gamma scalping system with neural network has potential and a further study may be needed to fine tune such system to have an acceptable profitable range.

\section{REFERENCES}

[1] Burton G. Malkiel, E.F.F., 1970. Efficient Capital Markets: A Review of Theory and Empirical Work. J. Finance

[2] Chang, T.-S., 2011. A comparative study of artificial neural networks, and decision trees for digital game content stocks price prediction. Expert Syst. Appl. 38, 14846-14851.

[3] Chen, A.-S., Leung, M.T., Daouk, H., 2003. Application of neural networks to an emerging financial market: forecasting and trading the Taiwan Stock Index. Comput. Oper. Res. 30, 901-923.

[4] Fernandez-Rodriguez, F., Gonzalez-Martel, C., Sosvilla-Rivero, S., 2000. On the profitability of technical trading rules based on artificial neural networks:: Evidence from the Madrid stock market. Econ. Lett. 69, 89-94.

[5] Guo, Z., Wang, H., Yang, J., Miller, D.J., 2015. A Stock Market Forecasting Model Combining Two-Directional Two-Dimensional Principal Component Analysis and Radial Basis Function Neural Network.

[6] Hassan, M.R., Nath, B., 2005. Stock market forecasting using hidden Markov model: a new approach, in: Intelligent Systems Design and Applications, 2005. ISDA'05. Proceedings. 5th International Conference on. IEEE, pp. 192196.

[7] Huang, W., Nakamori, Y., Wang, S.-Y., 2005. Forecasting stock market movement direction with support vector machine. Comput. Oper. Res. 32, 2513-2522.

[8] Kaboudan, M.A., 2000. Genetic programming prediction of stock prices. Comput. Econ. 16, 207-236.

[9] Kara, Y., Acar Boyacioglu, M., Baykan, Ö.K., 2011. Predicting direction of stock price index movement using artificial neural networks and support vector machines: The sample of the 
Istanbul Stock Exchange. Expert Syst. Appl. 38, 5311-5319.

[10] Khan, Z.H., Alin, T.S., Hussain, M.A., 2011. Price prediction of share market using artificial neural network (ANN). Int. J. Comput. Appl. $22,42-47$.

[11] Kim, K., Han, I., 2000. Genetic algorithms approach to feature discretization in artificial neural networks for the prediction of stock price index. Expert Syst. Appl. 19, 125-132.

[12] Kumar Chandar, S., Sumathi, M., Sivanandam, S.N., 2016. Prediction of Stock Market Price using Hybrid of Wavelet Transform and Artificial Neural Network. Indian J. Sci. Technol. 9.

[13] Kuo, R.J., Chen, C.H., Hwang, Y.C., 2001. An intelligent stock trading decision support system through integration of genetic algorithm based fuzzy neural network and artificial neural network. Fuzzy Sets Syst. 118, 21-45.

[14] Martinez, L.C., da Hora, D.N., de M Palotti, J.R., Meira Jr, W., Pappa, G.L., 2009. From an artificial neural network to a stock market daytrading system: A case study on the BM\&F BOVESPA, in: Neural Networks, 2009. IJCNN 2009. International Joint Conference on. IEEE, pp. 2006-2013.

[15] McCulloch, W.S., Pitts, W., 1943. A logical calculus of the ideas immanent in nervous activity. Bull. Math. Biophys. 5, 115-133.

[16] Mizuno, H., Kosaka, M., Yajima, H., Komoda, N., 1998. Application of neural network to technical analysis of stock market prediction. Stud. Inform. Control 7, 111-120.

[17] Perwej, Y., 2012. Prediction of the Bombay Stock Exchange (BSE) Market Returns Using Artificial Neural Network and Genetic Algorithm. J. Intell. Learn. Syst. Appl. 4, 108119.

[18] Sun, B., Li, T. k, 2010. Forecasting and identification of stock market based on modified RBF neural network, in: 2010 IEEE 17Th International Conference on Industrial Engineering and Engineering Management (IE EM). Presented at the 2010 IEEE 17Th International Conference on Industrial Engineering and Engineering Management (IE EM), pp. 424-427.

[19] Vanstone, B., Finnie, G., 2009. An empirical methodology for developing stockmarket trading systems using artificial neural networks. Expert Syst. Appl. 36, 6668-6680.

[20] Xiao, Y., Xiao, J., Lu, F., Wang, S., 2013. Ensemble ANNs-PSO-GA Approach for Dayahead Stock E-exchange Prices Forecasting. Int. J. Comput. Intell. Syst. 6, 96-114.

[21] Zekic, M., 1998. Neural network applications in stock market predictions-a methodology analysis, in: Proceedings of the 9th International Conference on Information and Intelligent Systems. Citeseer, pp. 255-263.

[22] Zhang, Y., Wu, L., 2009. Stock market prediction of S\&P 500 via combination of improved BCO approach and BP neural network. Expert Syst. Appl. 36, 8849-8854.

[23] "Stock Market Volatility and Learning - ADAM - 2016 - The Journal of Finance - Wiley Online Library."

[24] "Data | Free Full-Text | Current Core Competencies Trend of Small to Medium Enterprises (SMEs) in China-A Concurrent Comprehensive Evaluation and Active Learning Study of Newly Listed Chinese Stocks from 2015 through 2017."

[25] "The contribution of technology selection to core competencies - ScienceDirect."

[26] "Using artificial neural network models in stock market index prediction - ScienceDirect."

[27] "Application of artificial neural network for the prediction of stock market returns: The case of the Japanese stock market - ScienceDirect."

[28] "Predicting stock and stock price index movement using Trend Deterministic Data 
Preparation and machine learning techniques ScienceDirect."

[29] "Predicting the Direction of Stock Market Index Movement Using an Optimized Artificial Neural Network Model."

[30] Sharma, Nishchal. (2020). Index Option Greek Analysis with Heikin-Ashi Transformed Data and Its prediction with Artificial Neural Network. International Journal of Scientific Research in Computer Science, Engineering and Information Technology. 166-169. 10.32628/CSEIT206136.

[31] "A hybrid stock trading framework integrating technical analysis with machine learning techniques - ScienceDirect."

[32] “A Deep Neural-Network Based Stock Trading System Based on Evolutionary Optimized Technical Analysis Parameters - ScienceDirect."

[33] Sharma, Nishchal \& Chauhan, Chaman. (2019). Heikin-Ashi Transformation and Vix Index data for Stock Market Index Prediction and It's Effects. International Journal of Scientific Research in Computer Science, Engineering and Information Technology. 363-365. 10.32628/CSEIT195195.

\section{Cite this article as :}

Nishchal Sharma, "Gamma Scalping using Neural Network with Heikinashi Transformed Data and its Performance", International Journal of Scientific Research in Computer Science, Engineering and Information Technology (IJSRCSEIT), ISSN : 24563307, Volume 7 Issue 1, pp. 255-259, JanuaryFebruary 2021. Available at doi : https://doi.org/10.32628/CSEIT217152 Journal URL : https://ijsrcseit.com/CSEIT217152 